\title{
Rethinking Moral Expertise
}

\section{Nicky Priaulx, Martin Weinel \& Anthony Wrigley}

\section{Health Care Analysis}

An International Journal of Health Care Philosophy and Policy

ISSN 1065-3058

Health Care Anal

DOI 10.1007/s10728-014-0282-7

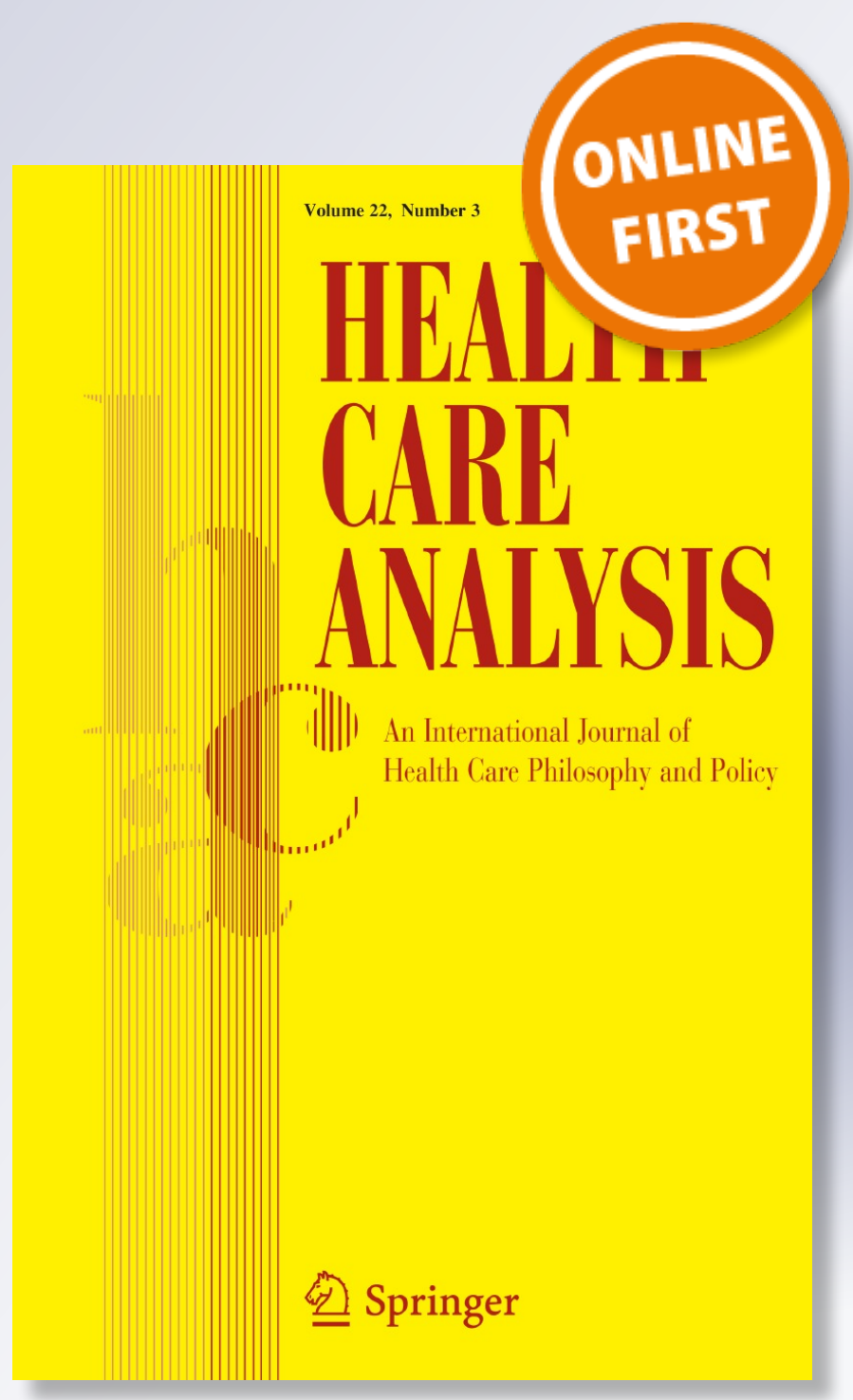

Springer 
Your article is protected by copyright and all rights are held exclusively by Springer Science +Business Media New York. This e-offprint is for personal use only and shall not be selfarchived in electronic repositories. If you wish to self-archive your article, please use the accepted manuscript version for posting on your own website. You may further deposit the accepted manuscript version in any repository, provided it is only made publicly available 12 months after official publication or later and provided acknowledgement is given to the original source of publication and a link is inserted to the published article on Springer's website. The link must be accompanied by the following text: "The final publication is available at link.springer.com". 


\title{
Rethinking Moral Expertise
}

\author{
Nicky Priaulx $\cdot$ Martin Weinel $\cdot$ Anthony Wrigley
}

(C) Springer Science+Business Media New York 2014

\begin{abstract}
We argue that the way in which the concept of expertise is understood and invoked has prevented progress in the debate as to whether moral philosophers can be said to be 'moral experts'. We offer an account of expertise that draws on the role of tacit knowledge in order to provide a basis upon which the debate can progress. Our analysis consists of three parts. In the first part we highlight two specific problems in the way that the concept of expertise has been invoked in the moral expertise debate, namely the understanding of expertise as an exclusive concept and the conflation of expertise with the idea of 'authority'. In the second part we suggest an alternative way of approaching the concept of expertise. This is based on Collins and Evans' sociological theory of expertises. This theory provides a valuable analytical framework for thinking about claims to expertise and for drawing the kinds of distinctions which allow for different kinds of moral expertises and competencies. In the final part, we show how the application of this theory helps to avoid some of the problematic conclusions which theorists have arrived at to date and provides a common platform for debate. Ultimately, it permits the argument to be made that moral philosophers could be considered specialist members of an expert community of moral decision-makers.
\end{abstract}

\footnotetext{
N. Priaulx $(\bowtie)$

Cardiff Law School, Cardiff University, Cardiff, UK

e-mail: PriaulxN@cf.ac.uk; Priaulxn@cardiff.ac.uk
}

M. Weinel

Centre for the Study of Knowledge Expertise Science (KES), Cardiff School of Social Sciences,

Cardiff University, Cardiff, UK

e-mail: Weinelm@cardiff.ac.uk

A. Wrigley

Centre for Law, Ethics and Society, Keele University, Keele, UK

e-mail: A.Wrigley@Keele.ac.uk 
Keywords Moral expertise $\cdot$ Bioethics $\cdot$ Moral philosophers $\cdot$ Laypersons · Sociology of expertise - Tacit knowledge

\section{Introduction}

The question of whether moral philosophers, when sitting on ethics committees or other deliberative bodies charged with making ethical judgements, can be considered moral experts has resulted in recent answers covering a wide range of possibilities. While some have strongly rejected the claim that moral philosophers are moral experts, others have argued that moral philosophers are a form of 'semiexpert'. Others still, by contrast, illustrate greater ambivalence on the matter, whether by highlighting moral expertise as just a desirable possibility, or by declaring the concept of expertise to be neither useful nor interesting, or by ducking the ambiguities of what expert status means in favour of exploring whether philosophers nevertheless can be said to perform a useful role. The argument that moral philosophers are 'full' moral experts in the sense that we attribute expertise to other professional areas, such as medicine or law, would seem to be rare; perhaps revealing that most are willing to concede that laypersons possess at least some relevant insight into moral matters in a way the precludes the identification of a privileged group of experts on the matter of morals.

While the aim of these debates is to ascertain when and in respect of what we should prefer the judgment of 'moral experts' over that of non-experts, gaining clarity on these issues in the context of moral matters is seriously hampered by how expertise is understood and used in the debates. As we will argue, these debates have accepted and turned upon an elitist conception of expertise which, in turn, has led to some rather implausible, if not unhelpful claims about moral expertise and the role of moral philosophers on deliberative bodies. The result is confused and clashing positions regarding the expertise of moral philosophers vis-à-vis members of the public.

To resolve the confusion, rather than following the approach of the existing debates by dwelling on the nature of ethics as the primary focus, ${ }^{1}$ our analysis takes the nature of expertise as a point of departure for thinking about moral expertise. This allows us to consider the question from a different perspective; namely, if this is what expertise amounts to, are moral philosophers experts in that sense? In order to answer this, we draw upon a so-called 'normative theory of expertises' that has been developed in science and technology studies. Collins and Evans provide one of the most complete accounts of expertise by constructing a substantive and multidimensional theory of expertises that links expertise to the acquisition of 'tacit knowledge'-the "knowledge that is not explicated", but which still plays a crucial role in all meaningful human activities. While tacit knowledge is of great importance for 'deep understanding' and mastering of specialist skills in domains such as high energy physics or moral philosophy, it is just as vital in mastering

\footnotetext{
1 Such as we might find in, e.g., where the objectivity of moral theory, the nature of moral experience and moral wisdom are all central to the determination of expertise.
} 
ubiquitous skills such walking on a crowded pavement or riding a bicycle in traffic. As we shall demonstrate, linking expertise to different bodies of tacit knowledgesuch as domain-specific or widely distributed (even ubiquitous) tacit knowledgemakes it possible to attribute different forms of expertises to different social groups (depending on what form of tacit knowledge they can draw upon). Using such a framework in the context of the debates about moral expertise allows us to describe what sort of expertises moral philosophers as well as lay members of the public possess in respect of moral matters.

The paper consists of three parts. In the first part we highlight two specific problems in the way that the concept of expertise has been invoked in the moral expertise debate, namely the understanding of expertise as an exclusive concept and the conflation of expertise with the idea of 'authority'. In the second part we outline important aspects of Collins and Evans' theory of expertises. This theory of expertises provides a valuable analytical framework for thinking about claims to expertise and for drawing the kinds of distinctions which allow for different kinds of moral expertises and competencies. Finally, we show how the application of this theory helps to avoid some of the problematic conclusions which theorists have arrived at to date and provides a common platform for debate. Ultimately, it permits the argument to be made that moral philosophers could be considered specialist members of an expert community of moral decision-makers. Such a specialism might consist of technical skills that allow moral philosophers to answer certain questions about the nature of morality and to provide certain key skills, such as logical analysis of moral argument, in a way that a lay person may not be able to. Critically however, what the framework of expertises also allows us to establish is that possession of such specialism is not the same thing as having a claim to some exclusive command of a domain of expertise in moral judgement. The nonexclusive account of expertise we draw from still allows for a much wider pool of experts in this area. The ultimate factor under consideration is that moral expertise consists in an ability to determine what to do with our knowledge of moral issues; it is the ability and capacity to exercise moral judgement rather than the possession of moral 'facts'. Accordingly, moral expertise is open to those who are not moral philosophers in this regard, as well as those who are.

\section{Morality, Authority and the Misconception of Expertise}

Perhaps as a consequence of the roles that moral philosophers perform for commissions and deliberative bodies, the question of expertise has been framed narrowly: whether moral philosophers are moral experts. Given that most moral philosophers undergo specialist training and interact with others in the philosophical community, with many performing broader consultative roles, one might expect to find robust justifications to the effect that moral philosophers do possess moral expertise. However, and perhaps somewhat surprisingly, most do not claim this. The peculiar nature of this position was noted by Peter Singer when he considered common assertions to the effect that 'there is no such thing as moral expertise' and that 'moral philosophers are not moral experts', leading him to question whether 
philosophers were right to disclaim expertise [17]. Yet several decades later, the same view dominates; as Archard notes: 'on the whole moral philosophers are sceptical about any claim that they possess moral expertise' [1].

Why moral philosophers should be reluctant to claim moral expertise can be attributed to the deployment of an under-theorised conception of expertise rather than innate concerns about the making of moral judgements. Problematic assumptions about what 'expertise' means and the legitimate scope of expert decision-making authority rest upon two serious misconceptions about expertise:

1. Expertise is treated as conferring absolute authority: This leads to the claim that having 'domain-specific expertise' on a matter-in this case the specific domain of morality-means that 'domain-specific experts' are afforded exclusive authority to speak on this matter.

2. Expertise is conceptualised as exclusionary and restricted: This is a result of expertise being equated with elite performance. It also means that many people engaged in making moral judgements such as novices, lay persons or citizens cannot be described as having expertise.

We therefore first need to account for these misconceptions about the nature of expertise before proceeding to a new assessment of what moral expertise amounts to in the final section.

\section{Misconception 1: Moral Expertise as Absolute Authority}

Much of the opposition by moral philosophers to the idea that they might be said to possess moral expertise can be linked to a concern that this is tantamount to saying that only moral philosophers can be experts in matters of morality, in the sense of being able to claim special authority to dictate what, for example, is morally right or wrong. This concern shapes Archard's approach to moral expertise: 'A claim of moral expertise is a claim to command knowledge in respect of the making of normative judgments not commanded by others' ([1], p. 123). Archard then goes on to argue that philosophers do not have the requisite command in respect of moral judgments on the grounds that moral philosophers accept and are committed to some version of common-sense morality, which he defines as - a 'set of moral maxims of which ordinary people have knowledge and of which they make use in their quotidian lives' ([1], p. 123). As a result, it cannot be claimed that philosophers are moral experts if they cannot claim to be better than ordinary people in exercising judgements about morality. Very similar considerations have also led others to reject or hedge the concept of moral expertise [10]. For example, Cowley argues that in respect of non-abstract moral quandaries like euthanasia, even if moral philosophers have greater familiarity with philosophical theory, they are no better situated than educated laypersons to determine what to do. The main arguments for and against euthanasia are well-known, of a 'personal' nature and 'not at all the "property" of the philosopher' [6]. In such cases, Cowley argues, there is no reason 
for affording special weight to a philosopher's view of what should be done. They, 'like everyone else' are invoking 'second order intuitions to stipulate that one consideration outweighs the other' [6]. Few, it is to be expected, would accept the concept where the effect is to suggest that moral philosophers have 'privileged knowledge on what is morally right' [10]. Yet even the exceptional few who do argue for moral expertise, notably Singer [17] and Gesang [12], neither venture so far as to say that moral philosophers possess 'command knowledge' in the sense of telling people what they must do. Indeed, it is difficult to identify any voice claiming that this is what moral expertise entails. The one notable exception being Gordon, who asserts, 'I believe that moral philosophers are moral experts and others should follow their advice' although he then goes on to admit that he provides no 'specific argument in support of this claim' ([14], p. 206). Instead, those arguing for moral expertise create a different picture of what this expertise must be like. Singer, for example, who considers the skills of moral philosophers, the advantages that their training provides them with in 'an understanding of moral concepts and of the logic of moral argument' as well as the time afforded to 'think full-time about moral issues', argues that,

[I]t would be surprising if moral philosophers were not, in general, better suited to arrive at the right, or soundly based, moral conclusions than nonphilosophers ([17], p. 117).

Rather than promoting a 'command model' of moral expertise, the emphasis here is on the kind of processes important to moral decision-making, including deliberation and reflection. Although some might balk at the idea of there being 'right' moral conclusions, it is reasonable to believe that most would at least subscribe to the view that some moral conclusions are better formed than others (rather than saying that moral philosophers are right). Unless one is inclined to believe that we already live in a perfect society, that anyone's moral views 'are as good as anyone else's' [17], or that one cannot improve one's moral decision-making, ${ }^{2}$ we might think it possible to say that the special work that philosophers perform can be constitutive of moral expertise in the sense that Singer outlines. This does not, however, necessitate saying that moral philosophers are the authority on morality who can profess what is right; nor importantly, does Singer suggest this. ${ }^{3}$

A more nuanced version of this argument emerges from Gesang's view that moral philosophers are 'semi-experts'. Echoing Singer, Gesang argues that 'moral judgments from moral philosophers will be better founded and more likely to be right than judgments from ordinary people' [12]. While placing strong weight on moral philosophers' exclusive knowledge of ethical theories, even Gesang accepts that 'moral philosophers cannot pronounce absolute wisdom' or say as a physicist could 'your opinion is false' [12]. Key to this is the operation of subjective moral intuitions. Though moral intuitions fall short of the moral knowledge necessary for a well-founded

\footnotetext{
${ }^{2}$ Although it is recognised that these views do exist and do create some challenging questions as to the nature of morality. See Cowley [6].

3 Our thanks to Peter Singer for confirming that our interpretation of his work was correct; Singer [18], February 4). Private Email Correspondence.
} 
moral judgment, Gesang [12] maintains that they remain a necessary part; he argues that because moral intuitions are shared by moral philosophers and laypersons, this means that 'moral philosophers are "semi-experts"'. Rather than arguing that moral philosophers have exclusive access to knowing what is morally 'right', he notes that 'their judgments can be criticized by any ordinary person who has different intuitions' but goes on to argue that there are 'good reasons to take their judgments very seriously and to have them serve on political committees'. This latter note is significant; despite the reluctance of some to accept the label of moral expert, most regard moral philosophers as serving an important role. ${ }^{4}$ Quite critically, this position is also occupied by Archard. While maintaining that the moral philosopher's role 'should not be that of invoking his expertise to ensure that what is done follows from his own better moral judgment of what should be done', Archard ([1], p. 127) nevertheless argues that:

Rather it ought to be that of advising and of 'coaching' non-philosophers, ensuring that they may come to see why the better judgment is a better judgment. If that is done conscientiously and successfully, then two desiderata are served; the better outcome is agreed and a general population is schooled in those skills that ensure they can play their proper part, as good citizens, in democratic self-government.

Given Archard's preparedness to say that moral philosophers can help others to identify better judgments and as such may exercise some form of expertise, Archard's view differs little in substance from Singer or Gesang's. Yet given his rejection of moral expertise, Archard is undecided on how to package the advisory and coaching capacity of moral philosophers. He concludes that while they cannot be shown to be moral experts, 'the better reason to think they are not shows that they are moral experts only in a limited sense' [1]. Overall, his position looks less coherent than that of Gesang's owing to the conflation of moral expertise with absolute authority on morality. While we later discuss the legitimate scope of expert decision-making, for the time being it will suffice to point to Crosthwaite [8], who notes that while ethicists and moral philosophers serve an important function in cases of moral uncertainty and conflict, suggesting that some "expertise" is being accessed, the concept of expertise does not, for him, mean that, 'one be unchallengeable by those who do not share one's training' [8].

\section{Misconception 2: Expertise as Exclusive}

While the study of expertise admits of a broader range of ways by which expert status is socially identified or measured, ${ }^{5}$ in conventional terms, expertise is understood as

\footnotetext{
${ }^{4}$ For an exception, see Cowley [7].

5 We can point to other factors which are closely associated with expertise; for example, common markers/signifiers of expertise can include things like credentials, track record and experience but also sometimes ones like money, success, influence and power. Moreover, expertise can also be highly associated with ideas of what kinds of skills are of particular social value and/or elite. As such, the label of expertise tends to be assigned to activities and skills which are not widely practised, to individuals engaged in highly technical work and high status professions, like medicine or science, rather than speaking English as a native language or the ability to cycle.
} 
referring to 'the characteristics, skills, and knowledge that distinguish experts from novices and less experienced people' [9]. Typically, the measures for identifying experts from non-experts centralise either 'superior' ${ }^{6}$ or 'evaluative" ability. In respect of both superiority and evaluative abilities, the approach taken is a relational (in context of expertise studies, 'relative') one where experts are studied in comparison to novices and the former constitute the more knowledgeable group with a higher level of proficiency than non-experts. In highly technical domains, where laypersons have little in the way of skills, knowledge or insight in respect of the work undertaken by specialists, this relative approach may cause fewer problems in its application.

However, in the case of moral expertise, where every commentator has noted the presence of ubiquitous skills in the form of 'common-sense morality', or 'subjective moral intuitions', the relative model of expertise quickly breaks down. It is in this respect that most of the engagements with question of moral expertise become objectionable. The question as to what 'special skills' the moral philosopher could be said to possess gets lost because the issue of possessing some specialist skills in morality gets conflated with the issue of possessing moral expertise. This is troublesome because under the relative model, expertise is regarded as an exclusive matter that only the specialist can possess:

Expertise is exclusionary and restricted. It is the command of knowledge within a defined domain by some persons that is not commanded by others ([1], p. 120).

This understanding of expertise has come to define the debate around moral expertise. ${ }^{8}$ Under the relative view one is either an expert or one is not; one creates the other. But on this model it is not always easy to spot who the expert is. In cases where an activity or body of knowledge is ubiquitous-highly spread across the general population - the tendency is to think of those activities or knowledge as not forming the basis of expertise. Furthermore, where there are subtle variations in competency or variations in how that activity is performed, for example when one is training to become a doctor, it becomes harder to define when expertise is actually achieved. This is largely owing to the crudeness of the relative expertise model. It is typically an all or nothing matter, its principal target is exclusivity, and it possesses no reliable measures for detecting the presence of subtle differences in competency or developing expertise. As such, when confronted with subtle differences and developing capacities in population-wide activity, the model breaks down. Perhaps for understandable reasons in the face of activities that have strong ubiquitous elements some are driven to say, 'there are no experts at all'. In respect of moral expertise this is just the conclusion which David Archard reached; although the option he speedily rejected was that everyone could be said to possess expertise:

\footnotetext{
${ }^{6}$ Superiority is evaluated by focusing upon the performance of domain-related tasks, whether by measuring consistency in the achievement of specific outcomes, such as diagnosis of medical conditions.

7 In respect of evaluative ability, there is broad acceptance that while experts may not always demonstrate superior ability to perform tasks central to experts, such as selecting stocks or weather forecasting, 'the experts are nearly always the best qualified to evaluate their own performance and explain the reasons for any deviant outcomes', Ericsson [9].

${ }^{8}$ As exemplified by Gordon [14], Cowley [7] and Gesang [12].
} 
It does not normally make sense to say that everyone is or can be an expert in some matter. The phrase 'We are all now experts in $\mathrm{X}$ ' is surely typically employed, somewhat ironically, to indicate the end of expertise and the 'democratization' of knowledge in the domain. Recognition of expertise gives the non-expert a good reason to endorse the judgment of the expert, a judgment she would not otherwise make or have a good reason to make ([1], p. 120).

Archard's broader analysis around the moral capacity of laypersons vis-à-vis the moral philosopher is both plausible and compelling. It is clear that he sees ordinary people as holding the capacity to be moral, and it is also clear that he regards moral philosophers as being engaged in a distinctive range of activities which is socially valuable in respect of morality. He doesn't want to deny either of these positions or to say that moral philosophers are no different to everyone else. What is singularly responsible for wreaking havoc on the overall reasoning is reliance on a relative model of expertise. In affording no wiggle room for addressing differences in skill, the choice appears to be between: declaring the philosopher to be the moral expert or saying that everyone is a moral expert. For Archard, neither is desirable. The idea that recognising expertise universally somehow poses dangerous repercussions for society drives a wellintended critique to the conclusion that 'there are no ethical experts' is better. But this doesn't stack up; on this model of expertise at least there is no real substantive difference between saying none of us are experts or all of us are. Either way the conclusion should be seen as lamentable when most commentators, including Archard, can identify some kind of specialist skill at play.

It is important to see that the relative model of expertise will always invite us to reach precisely these kinds of untenable positions. Some, appreciating these problems, have attempted to identify alternative solutions which avoid the all-or-nothing approach, for example the idea that moral philosophers might be 'semi-experts' [12] but these constitute ad-hoc revisions of a problematic model and increases the potential for a confused semantic battle that we should seek to avoid. As we sought to illustrate, even commentators holding remarkably similar positions have nevertheless clashed on the question of moral expertise. The key problem which afflicts all of these approaches is how expertise has come to be understood. Given the importance of subjective moral intuition and laypersons capacity to develop better moral judgment, where expertise is understood as entailing moral exclusivity and moral authority, most moral philosophers will be driven to the conclusion that there is no such thing as 'moral expertise' or 'moral experts'. This is not a helpful way of identifying what moral philosophers are specialist at, why we should listen to them and in respect of what matters they can be said to 'know what they are talking about'. What is clear is that we need a different set of tools by which to evaluate specialism. For this, we turn to consider the vehicle that will take us forward.

\section{The New Sociology of Expertises}

Collins and Evans' theory of expertises has been formulated in the context of debates about expertise in the field of science and technology studies (STS) [3]. Their conception of expertises can, however, also contribute something to the 
philosophical debate about 'moral expertise' as it avoids the two misconceptions about expertise worked out in the previous sections. The cornerstone of Collins and Evans' sociological conception of expertise is to link the acquisition of expertise to the acquisition of tacit knowledge relevant to particular domains. This means that those who possess the tacit knowledge relevant to a domain can be regarded as experts. Tacit knowledge is a challenging concept to precisely define but it refers to knowledge that is not and, to some extent, cannot be made explicit [2]. By contrast with explicit knowledge, which can be expressed in formal language and shared through texts, manuals or explanation, tacit knowledge is difficult to formalise. It relates to the numerous 'unwritten' rules and areas of discretionary judgement that operate within every domain of human activity. As Nonaka et al. [15] note, tacit knowledge is 'deeply rooted in action, procedures, routines, commitment, ideals, values and emotions' and describes an 'analogue process that requires a kind of 'simultaneous processing'. It is the knowledge that makes the deep understanding of explicit knowledge possible. It is the knowledge that enables us to apply explicit knowledge in new situations and under changing circumstances. It is also the knowledge that makes the acquisition and the appropriate use of explicit knowledge possible. While it cannot be directly observed, tacit knowledge manifests itself in people's abilities. Without the ability to talk or to act in a way that indicates to others that a person knows what she is talking about or is doing, there is no point in calling someone an expert. ${ }^{9}$ One crucial aspect of tacit knowledge is that it is to some extent a collective property, which means that bodies of tacit knowledge are 'developed' and 'maintained' within social groups [4]. The only known way for an individual to tap into these group-specific 'reservoirs' of tacit knowledge is to actively immerse themselves into a social group that possesses it.

This has profound consequences for the distribution of expertises within societies, thereby challenging the idea that expertise is necessarily something exclusive. If it is accepted that tacit knowledge is involved in every meaningful or intentional human practice [5] then this allows for 'ubiquitous expertises' related to domains are accessible to everyone (or ubiquitous). An example of the former is the ability to speak a natural language which is a tacit knowledge laden activity. ${ }^{10}$ Everyone, or almost everyone, in the United Kingdom can learn to speak English fluently by just living in the country and interacting with other English language speakers on a regular basis. Thus, the ability to speak English in the UK is ubiquitous but since it is a tacit knowledge laden activity, it is also recognised as a domain of expertise by Collins and Evans' theory of expertises. ${ }^{11}$

Of course not every skill is widely distributed in a society. Accordingly, Collins and Evans [3, 4] distinguish between 'ubiquitous expertises' and 'specialist

\footnotetext{
9 The importance of language is stressed by Collins [2]; see also [16]. It has to be pointed out that not all people who are able to do something expertly are able to talk about it in a way that reflects their expertness; to be able express oneself adequately requires 'interactive ability' [4].

${ }^{10}$ If it was not than we should already be surrounded by robots that speak natural languages fluently or we should have translating devices (such as Google translate) that actually work perfectly.

11 Note that speaking English fluently is considered to be a specialist skill in non-English speaking countries such as Spain or Italy.
} 
expertises'. ${ }^{12}$ Specialist expertises are related to 'domains of knowledge' which form around particular activities and are associated with particular subgroups of larger collectives. Scientific disciplines are paradigmatic examples of such 'domains of knowledge', but in principle any meaningful activity that is not widely shared might be regarded as a 'domain' that may give rise to specialist expertises. For example, to become a competent astrophysicist, it is not sufficient to just live in a country where astrophysics is practised by a subset of the population. What is needed to gain 'fluency' is to immerse oneself into the community of astrophysicists, either by enrolling in a University course and then working in the field or by talking to astrophysicists on a regular basis about domain-relevant 'stuff'. ${ }^{13}$

By accommodating ubiquitous and specialist forms of expertises, Collins and Evans' theory avoids creating an exclusionary concept of expertise. Their conception of expertise also avoids establishing a fixed connection between expertise and decision-making authority. That means that in cases where specialist expert knowledge is considered to be relevant for wider society-affecting decisions, overall decision-making authority is not simply afforded to experts. Collins and Evans' [3, 4] theory of expertise only states that whilst technical expertise possesses authority in respect of technical matters, it does not hold determinative authority in respect of broader policy decisions (that deploy technical knowledge) which ought to be made by the appropriate policy-making institutions. They therefore distinguish between a 'technical' and a 'political' phase of decision-making [11].

\section{Rethinking Moral Expertise}

While the work flowing from the theory of expertise is far richer and more extensive than we can capture here, the aim has been to introduce the key driver for rethinking how expertise might be captured in the case of the moral philosopher's role when it comes to making ethical judgements on deliberative bodies. At the heart of the theory of expertise sits tacit knowledge and its concomitant means of determining what it is that generates expertise in any given domain of knowledge. In applying this account of expertise to the case of moral decision-making, it is apparent that it is neither necessary nor sufficient that one is a moral philosopher in order to make a

\footnotetext{
12 The distinction between ubiquitous and specialist expertise has mainly heuristic value. The boundary between the two is fluid and fuzzy and depends on the frame of reference. For example, the ability to speak English fluently is 'ubiquitous' if only the population of the UK is considered. In the context of talking about the entire human population, speaking English is an ability of a certain sub-population and is therefore not 'ubiquitous'. Similarly, while writing can be considered to be a ubiquitous skill in presentday Britain, only a few 100 years ago, writing was considered to be skill mastered only by some in the UK. Moreover, in some parts of the world, the ability to write is still not ubiquitous.

13 That the latter is possible has been demonstrated by Harry Collins, who has, in his role as sociologist of science, immersed himself for three decades into the community of gravitational wave physicists and talked to many practitioners [13]. While Collins is unable to 'do' gravitational wave physics, he has gained enough fluency in gravitational wave physics to become talk about aspects of it in a way that makes him indistinguishable from trained gravitational wave physicists. Note that in contrast to talking to those who possess tacit knowledge, reading alone, even reading domain-specific literature, is insufficient to acquire tacit knowledge needed for the deep understanding of a domain as tacit knowledge cannot be transferred by means of written text.
} 
claim of moral expertise. Instead, a number of important clarifications as to the nature of moral expertise can be made. First, there is such a thing as moral expertise, both in a 'ubiquitous' and 'specialist' sense of expertise, as outlined in the previous section. Second, this is not a blanket claim that everyone is a moral expert or that everyone's moral judgements are as good as everyone else's. Third, moral philosophers are not precluded from being moral experts; it is just that they do not possess this attribute simply by virtue of being moral philosophers. Fourth, those who are not moral philosophers can also lay claim to being moral experts. Fifthly, because moral decision-making can involve a certain amount of specialist knowledge, it can be argued that moral philosophers have a specialist status in deliberative bodies in providing certain aspects of specialist knowledge about morality. In this last section, we briefly outline how and why these clarifications about moral expertise can now be made.

The theory of expertises allows for expertise to exist across a very broad range of human activity, from ubiquitous activities such as walking or crossing the street, through to specialist activities such as computer programming and quantum physics. This stands in contrast to Archard's [1] claim that '[e]xpertise is exclusionary and restricted'. When it comes to contextualising this general theory of expertise, the central question is 'who knows what they are talking about?'. In applying this to the case of moral expertise, it would seem that what moral philosophers do and what laypeople do is remarkably similar-they exercise moral judgements based on common-sense ideas about morality. In this regard, we agree with Archard's [1] analysis that 'moral philosophers share with non-philosophers a general or basic moral knowledge' and that 'philosophers do not command a comprehensive knowledge within the domain of normative judgements denied to non-philosophers'. Where, however, Archard sees this as supporting his view that moral philosophers cannot be moral experts on the grounds that they do not possess an ability to make judgements that non-philosophers somehow cannot make, on the Collins and Evans' model of expertise this is what establishes both the moral philosopher and the lay-person as being able to lay claim to moral expertise.

The ultimate factor is that moral expertise resides in an ability to determine what to do with our knowledge of moral issues; it is the ability and capacity to exercise moral judgement. One does not need to be a moral philosopher in order to do thismany people exercise this capacity on a regular basis and hence allow a claim that there are levels of ubiquitous moral expertise that are widely distributed throughout society. However, in order to be able to fully endorse this view in the case of moral expertise we need to clarify the second point: that this view is not a blanket claim that everyone's moral judgements are as good as everyone else's or that laypersons are similarly situated to moral philosophers.

Let us separate two aspects of what is entailed in exercising moral judgement. Firstly, there is the capacity in which most rational agents exercise moral judgements in order to make decisions on a wide range of normative matters in everyday life. This is a form of ubiquitous expertise shared by most people in society. Whether people agree or disagree with each other over the specific moral decisions made by others is largely irrelevant for the exercise of this skill. The point is that making moral judgements is embedded in a wide range of our social 
activities. As such, the tacit knowledge necessary for processing morally relevant information and making judgements accordingly is possessed by a large proportion of the population. However, the question before us is whether moral decisionmaking could also admit of a more specialist character, for example, as is practised in making complex or highly formalised normative judgements that is required in deliberative bodies. There is no doubt that it can be claimed such work entails some kind of specialism, but importantly, the issue is how this can both afford the moral philosopher a specialist status in the relevant expert community while not precluding non-moral philosophers from being considered moral experts.

Under the Collins and Evans' account, expertise is determined through the acquisition of tacit knowledge which can be obtained only by those who immerse themselves in the relevant domain and group. The specialist domain of ethical deliberative decision-making bodies is populated by people who have 'tapped into' this reservoir of tacit knowledge about how to exercise moral judgements in this regard. This is not to say that simply joining such a body automatically makes one a specialist expert, only that it is the route to becoming such an expert. Once part of such a body, an individual is socially immersed in the range of activities and practices that make one an effective member of a deliberative body. Although some of this might involve the acquisition of explicit knowledge, such as information about regulations, resources, political and public opinions, and so forth, expertise amounts to more than this because it is the product of the tacit knowledge one acquires in that field. Such tacit knowledge can be extremely subtle in nature and may not be discernible to a non-expert but it is precisely the acquisition of this sort of tacit knowledge that marks out the expert from the non-expert [19]. The tacit knowledge involved in sitting on deliberative bodies is therefore expertise in a specialist sense because the sort of tacit knowledge required is only to be gained from experiencing the activities and practices that take place in such bodies.

This also feeds into the third and fourth points raised as to the nature of moral expertise by allowing both moral philosophers and non-philosophers alike to lay claim to moral expertise in this specialist sense. Exercising moral judgement, knowing what we should do with the information we have about an issue, is something that people may be better or worse at. It may even be something that the moral philosopher has some advantage in doing well given the amount of time they spend in considering matters of morality. However, an argument as to how moral philosophers might lay claim to possessing specialism would look like this:

Knowing a great deal about moral theory or philosophical method is not what constitutes possession of the requisite tacit knowledge about moral decisionmaking; rather the relevant tacit knowledge here consists of knowing how to implement and apply explicit knowledge of moral matters to the issue at hand.

Of course, much hangs on what this explicit knowledge of morally relevant matters is but this is not the central concern as to what determines expertise. This may still leave a genuine confusion as to what role moral philosophers could lay claim to that is in any way different from any other moral expert. This is the fifth and final point that needs clarification. 
Although it is true that most people have a ubiquitous form of moral expertise and that some also have a specialist expertise suited to moral decision-making on deliberative bodies, moral philosophers can be distinguished further in terms of being able to provide certain aspects of specialist knowledge, such as the analytical skills pinpointed by Singer. This, however, is the provision of a specialist technical role that moral philosophers may play in deliberative bodies by providing explanation of, for example, consistency in moral reasoning or the implications of pursuing a particular theoretical line, rather than a necessary component of what constitutes expertise itself. Certainly, one may be an expert moral philosopher through possession of the tacit knowledge acquired through social immersion in the field of moral philosophy that gives the explicit knowledge of, for example, moral theory and logical argument, its meaning. This is what demarcates someone who has grasped elements of explicit knowledge about moral philosophy from an expert moral philosopher: only the moral philosopher has tacit knowledge that allows them, for example, to know when to take a particular journal article or author seriously, how to convey an advancement in moral argument to a philosophy conference, or to recognise patterns in critical approaches to certain types of moral argument. These elements may never be written down as explicit, were that even possible in all cases, but knowing them is the product of tacit knowledge acquired in the field of moral philosophy which is unavailable to others. It is therefore possible to argue that the moral philosopher holds a particular status in an expert community through the possession of specialist tacit knowledge in the nature of ethical reasoning that others may not be able to provide, even with specialist expertise in an area involving moral deliberation.

\section{Conclusion}

We have arrived at a point where it is both possible and plausible to claim that moral philosophers are moral experts. Importantly, this does not entail saying that moral philosophers are the ultimate source of authority on morality, or that laypersons lack expertise. Accepting that morality is a ubiquitous disposition and undoubtedly a talent that we can (and desirably will) develop; it seems problematic to claim that ordinary people lack any expertise in matters of morality. It may be that some better exhibit the kinds of skills and dispositions that are necessary for robust moral judgment and some to a far lesser degree so that we might think their decision-making process lacking. While moral philosophers may be uncomfortable with their skills in morality being seen as no different in substance to laypersons we should not be quick to say that all laypersons are equal in moral reasoning. Instead a more dynamic evaluation of expertise is needed to deal with different competencies and skills. This evaluation, in turn, will reveal what it is in terms of specialist skills and knowledge that expert moral philosophers can contribute to ethical decision-making on matters of public policy.

\section{References}

1. Archard, D. (2011). Why moral philosophers are not and should not be moral experts. Bioethics, 25, 119-127.

2. Collins, H. (2010). Tacit and explicit knowledge. Chicago: University of Chicago Press. 
3. Collins, H., \& Evans, R. (2002). The third wave of science studies: Studies of expertise and experience. Social Studies of Science, 32, 235-296.

4. Collins, H., \& Evans, R. (2007). Rethinking expertise. Chicago: The University of Chicago Press.

5. Collins, H. M., \& Kusch, M. (1998). The shape of actions: What humans and machines can do?. Cambridge, MA: MIT Press.

6. Cowley, C. (2005). A new rejection of moral expertise. Medicine, Health Care and Philosophy, 8, 273-279.

7. Cowley, C. (2012). Expertise, wisdom and moral philosophers: A response to Gesang. Biothics, 26, 337-342.

8. Crosthwaite, J. (2005). In defence of ethicists. A commentary on Christopher Cowley's paper. Medicine, Health Care and Philosophy, 8, 281-283.

9. Ericsson, A. K. (2006). An introduction to Cambridge handbook of expertise and expert performance: Its development, organization and content. In K. A. Ericsson, N. Charness, P. J. Feltovich, \& R. R. Hoffman (Eds.), The Cambridge handbook of expertise and expert performance. Cambridge: Cambridge University Press.

10. Eriksson, S., Helgesson, G., \& Segerdahl, P. (2006). Provide expertise or facilitate ethical reflection? A comment on the debate between Cowley and Crosthwaite. Medicine, Health Care and Philosophy, 9, 389-392.

11. Evans, R. J., \& Plows, A. (2007). Listening without prejudice? Re-discovering the value of the disinterested citizen. Social Studies of Science, 37(6), 827-853.

12. Gesang, B. (2010). Are moral philosophers moral experts? Bioethics, 24, 153-159.

13. Giles, J. (2006). Sociologist fools physics judges. Nature, 442, 8.

14. Gordon, J.-S. (2014). Moral philosophers are moral experts! A reply to David Archard. Bioethics, 28, 203-206.

15. Nonaka, I., Toyama, R., \& Konno, N. (2000). SECI, Ba and leadership: A unified model of dynamic knowledge creation. Long Range Planning, 33(1), 5-34.

16. Selinger, E., Collins, H. M., \& Dreyfus, H. L. (2007). Interactional expertise and embodiment. Studies in History and Philosophy of Science, 38(4), 722-740.

17. Singer, P. (1972). Moral experts. Analysis, 32, 115-117.

18. Singer, P. (2013). Private email correspondence.

19. Weinel, M. (2007). Primary source knowledge and technical decision-making: Mbeki and the AZT debate. Studies in History and Philosophy of Science, 38, 748-760. 